\title{
Implement and soil condition effects on tillage-induced erosion
}

\author{
J.R. Marques da Silva ${ }^{\text {a } *}$, J.M.C.N. Soares ${ }^{\text {a }}$, D.L. Karlen ${ }^{\text {b }}$ \\ a Departamento de Engenharia Rural, Universidade de Évora, P.O. Box 94, P-7002-554 Évora, Portugal \\ ${ }^{\mathrm{b}}$ USDA-ARS, National Soil Tilth Laboratory, 2150 Pammel Dr., Ames, IA 50011-4420, USA
}

\begin{abstract}
Water, wind, or tillage-induced soil erosion can significantly degrade soil quality. Therefore, understanding soil displacement through tillage translocation is an important step toward developing tillage practices that do not degrade soil resources. Our primary objective was to determine the effects of soil condition (i.e. grassland stubble versus previously tilled soil), opening angle, and harrow speed on soil translocation. A second field study also conducted on a Lixisol but only in the stubble field, quantified displacement effects of mouldboard ploughing. The field studies were located $12 \mathrm{~km}$ South of Évora, Portugal. Soil displacement or translocation after each tillage operation in both studies was measured using aluminium cubes with a side length of $15 \mathrm{~mm}$ as 'tracers'. Offset angles for the harrow disk were $20^{\circ}, 44^{\circ}$ and $59^{\circ}$; tractor velocities ranged from 1.9 to $7.0 \mathrm{~km} \mathrm{~h}^{-1}$ and tillage depth ranged from 4 to $11 \mathrm{~cm}$. The depth of mouldboard ploughing was approximately $40 \mathrm{~cm}$ with a wheel speed of $3.7 \mathrm{~km} \mathrm{~h}^{-1}$. The translocation coefficients for the two implements were very different averaging $770 \mathrm{~kg} \mathrm{~m}^{-1}$ for the mouldboard plough and ranging from 9 to $333 \mathrm{~kg} \mathrm{~m}^{-1}$ for the harrow disk. This shows that the mouldboard plough was more erosive than the harrow disk in these studies. All three variables (soil condition, opening angle, and tillage velocity) were critical factors affecting the translocation coefficient for the harrow disk. Displacement distances were the largest for compacted soils (stubble field), with higher opening or offset angles, and at higher velocities. The results also showed significant correlation for (a) mean soil displacement in the direction of tillage and the slope gradient and (b) soil transport coefficient and the opening angle. Our results can be used to predict the transport coefficient (a potential soil quality indicator for tillage erosion) for the harrow disk, provided tillage depth, opening angle, and tool operating speed are known.
\end{abstract}

(c) 2004 Elsevier B.V. All rights reserved.

Keywords: Soil translocation by tillage; Soil quality; Mouldboard; Offset disc harrow

\section{Introduction}

Tillage erosion is the down-slope displacement of soil through the action of tillage. The process was recently identified as an important factor in the study of soil erosion (Lindstrom et al., 1992; Lobb et al., 1995; Revel et al., 1993; Govers et al., 1994; Poesen et al.,

\footnotetext{
* Corresponding author. Tel.: +1-351-266-760823; fax: +1-351-266-711189.

E-mail address: jmsilva@uevora.pt (J.R. Marques da Silva).
}

1997; Turkelboom et al., 1997; Quine et al., 1999; Montgomery et al., 1999; Van Muysen et al., 1999), of soil constituent and amendment dispersion (Sibbesen, 1986; Monreal et al., 1995; Kachanoski et al., 1997; Quine et al., 1996) and for quantifying spatial variability in soil quality for agricultural lands (Kachanoski et al., 1985; Marques da Silva and Soares, 2001). Soil translocation is often expressed as the average length of displacement, which is equivalent to the volume of translocated soil per unit width of tillage divided by the depth of tillage. It is also expressed as a mass by 